\title{
Automated door access based on RFID using Arduino
}

\author{
Ramsha Suhail ${ }^{1}$ \\ \{suhailramsha100@gmail.com ${ }^{1}$ \} \\ Indira Gandhi Delhi technical university for womens (IGDTUW), New Delhi ${ }^{1}$
}

\begin{abstract}
With the rising interest for security, framework with high reliance and fast reaction frameworks are real need for industries and the ventures. RadioFrequency Identification is the most significant region of future and is increasing huge consideration from a logical world and enterprises. In this work, RFID based door access control utilizing Arduino is created. We used RFID ID tag and RFID reader, which is used to match the data on tag with the data in the database program which leads to movement of door by confirming whether the data is correct and/or incorrect. Opening of the door uses servo motor that gets its feed from Arduino board. The opening and closing is based on the flag set by the Arduino response. When the flag is set to 1 , the door opens and if it is set to 0 , the door remains closed. The LED based on the feed also comes from the Arduino board.
\end{abstract}

Keywords: RFID card, Door control access, Arduino UNO

\section{Introduction}

Since innovation is so cutting-edge, one of a kind access control frameworks have turned out essential to win security dangers to different associations. Access control framework confines access to a property, a structure, or a space to approved people [1]. In the field of data and protection security, door access control frameworks are assuming major indispensable jobs to shield associations [2]. This is where everything is related with the framework, where anyone can get hold of information from wherever around the world. In this manner, hacking of one's data is a noteworthy issue. On account of these perils, it is basic to have a type of individual recognizable proof (ID) to get to one's own specific data. Security get to framework is exceptionally helpful to use at home, office and business structures [3]. Every one of these years, different frameworks are acquainted with track the individual's development. Among standard individual ID systems, secret key and ID card strategies are the most watched techniques. Be that as it may, it isn't hard to hack password now and recognizable ID cards may get lost, henceforth making these strategies very sketchy. With the upgrade in the innovation, Framework Security is getting to be thought of significant worry in different associations and consequently advanced locks have turned into a significant piece of these security frameworks. There are numerous sorts of security frameworks that are accessible for security of our place. [4]

\section{RFID Technology}


Radio Frequency Identification abbreviated as RFID, is a progressive development that can be used to advance the passageway control framework [5] [6]. It gives a robotization in different procedures extending from mechanical parts to home control. RFID innovation will assist us with developing a door access control framework which can permit the passage of approved faculty in the confined zones [7]. Additionally this innovation is utilized prominently in charge get to frameworks which has wide scope of uses in regions, for example, staff distinguishing proof, customer products following, etc[8].RFID frameworks are essentially a blend of RFID innovation and figuring innovation. They principally comprises of three segments in particular examiner (reader), transponder (tag) and PC containing database. The reader goes through the content of different labels and transmit content to the server for confirmation. When the data is prepared and checked, get to is conceded. This RFID framework gives a wide scope of frequencies from low recurrence range to microwave recurrence range. With the expansion in the quantity of illicit sections over the previous decade, different organizations and workplaces empower creation and establishment of robotized door security frameworks. These frameworks are planned to give wellbeing to confined room in companies, shops and workplaces [9]. This mechanized frameworks gives upheld section and diminishes the odds of robbery. RFID based security framework utilizing Arduino Figure.1 has a RFID reader joined to it. RFID reader reads the one of a kind alphanumeric code of RFID labels and sends it to Arduino. At that point Arduino distinguishes whether RFID card is substantial or invalid. On the off chance that the card is invalid, at that point framework turns on the ringer. Be that as it may, on the off chance that the RFID card appeared by the client is legitimate, at that point the servo engine is turned on and door open $[10]$.

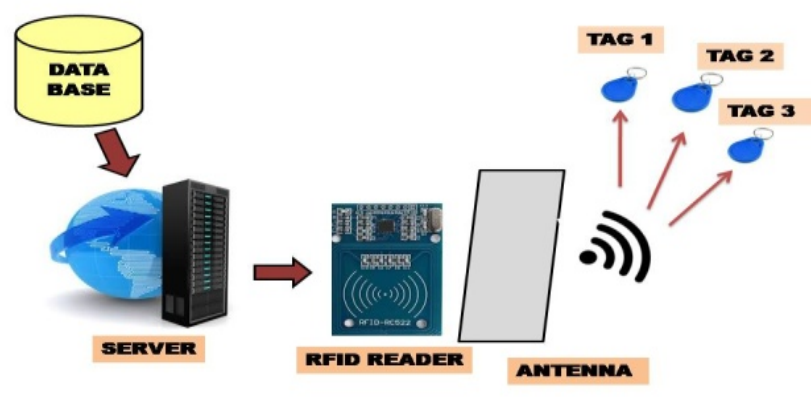

Fig. 1. RFID Control access system

\section{Simplified block diagram}




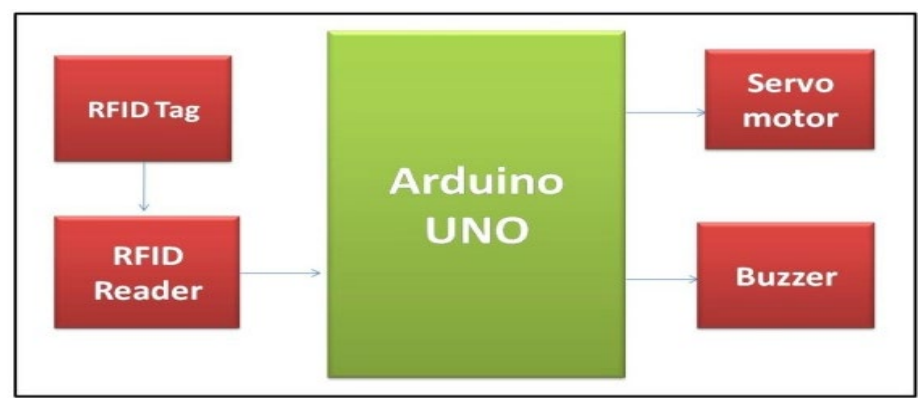

Fig. 2. Block diagram of system model

The block diagram in Figure 2. shows the connection between the various blocks. These blocks together define the functionality of Arduino UNO. We used RFID ID tag and RFID reader, which is used to match the data on tag with the data in the database program which leads to movement of door by confirming whether the data is correct and/or incorrect. Opening of the door uses servo motor that gets its feed from Arduino board. The opening and closing is based on the flag set by the Arduino response. When the flag is set to 1 , the door opens and if it is set to 0 , the door remains closed. The LED and buzzer based on the feed also comes from the Arduino board.

\section{Hardware components}

The framework dependent on this model is introduced at the passage of the restricted room. In this created work, we require the RFID Module, RFID tag, and servo engine to see the controlling framework. It could utilize a minimized hardware worked around the Arduino UNO board. The project could be created in embedded $\mathrm{C}$. The segments required in the model are as follows:

\subsection{Arduino UNO board}

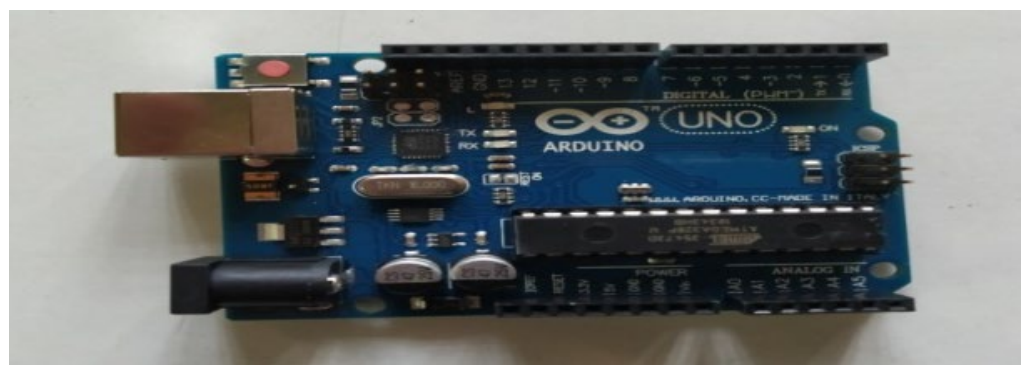

Fig. 3. Arduino UNO board [22]

Arduino UNO is an open-source microcontroller board dependent on the Microchip ATmega328P microcontroller. It utilizes a type B USB port for power. It is programmable with a product called ARDUINO IDE (incorporated improvement condition) [11]. In our work, we have utilized an Arduino board as appeared in Figure 3. 


\subsection{RFID Module}

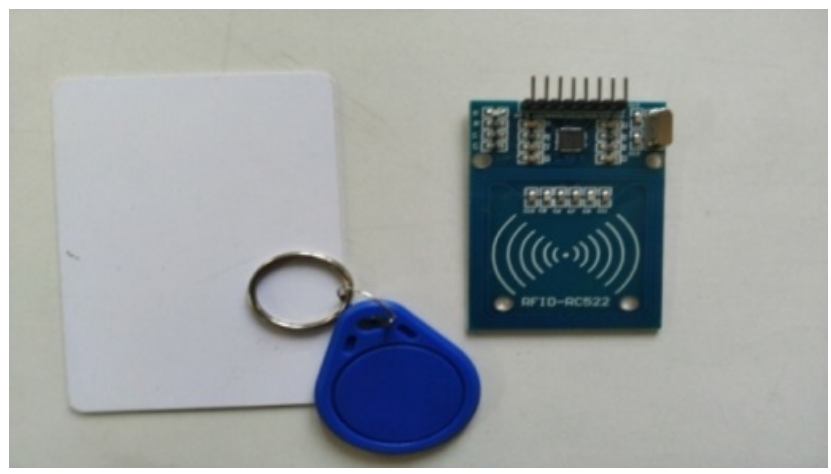

Fig. 4. RFID Tag and RFID Reader[22]

RFID is contracted as Radio Frequency Identification. It makes a remote correspondence and empowers information move between RFID tag and RFID reader [12] [13]. This module can read and compose information without direct contact. The RFID label comprises of kilobytes of rich data in it. The RFID reader is a functioning segment .The RFID tag, then again, is a detached segment that is situated on the item we need to distinguish. It has an antenna attached to a microchip. So as we place the tag is near the scope of RFID reader than some voltage is created in reception apparatus curl and voltage act as power. In our work, we have utilized RC522 MODULE to get to door control framework Figure 4.

\subsection{Servo motor}

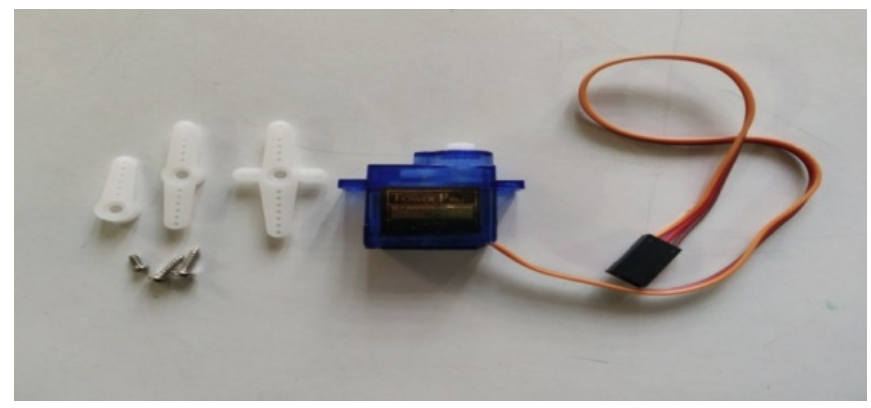

Fig. 5. Servo motor[22]

A servomotor control the angular position, speed, and acceleration. It comprises of a reasonable engine coupled to a sensor for position feedback [15]. Servomotors have various applications in the field of mechanical autonomy, computerized producing and so on. Engine 
in our work is to open and close the door consequently when the RFID per user recognizes the RFID tag of the client Figure 5.

\subsection{Light emitting diode}

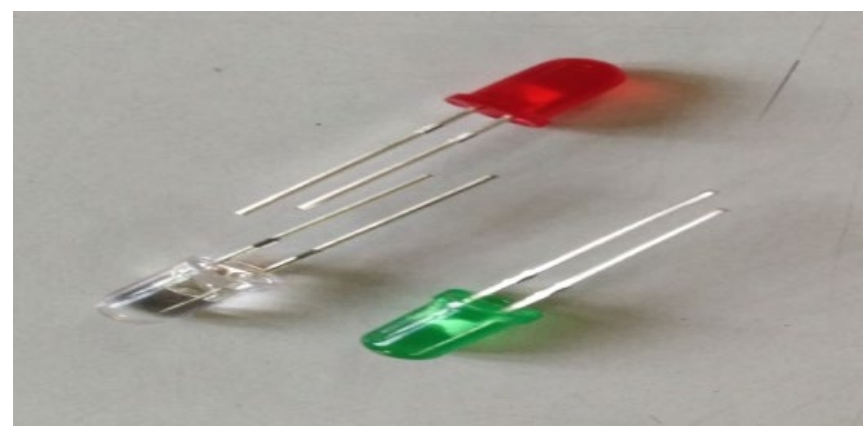

Fig. 6. LED[22]

A light emitting diode is a diode that produces visible light when an electric current goes through it [16]. They are profoundly effective and produces monochromatic light. In our work, we have utilized 3 LEDs Figure.6.

\subsection{Jumper cables}

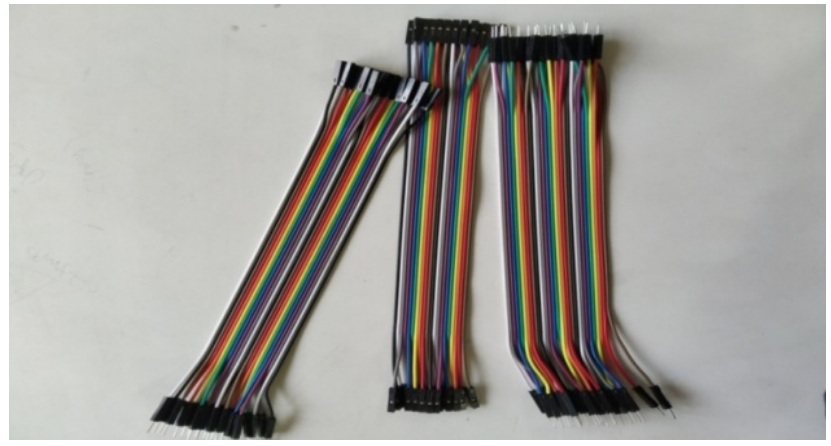

Fig. 7. Jumper cables [22]

Jumper links are utilized to move electric flow from one point to other inside a circuit. Because of high conductivity, jumper links are made of copper and aluminum [17]. In this model, we have utilized three mix of jumper link for example male to male, female to female and male to female Figure.7.

\subsection{Buzzer}




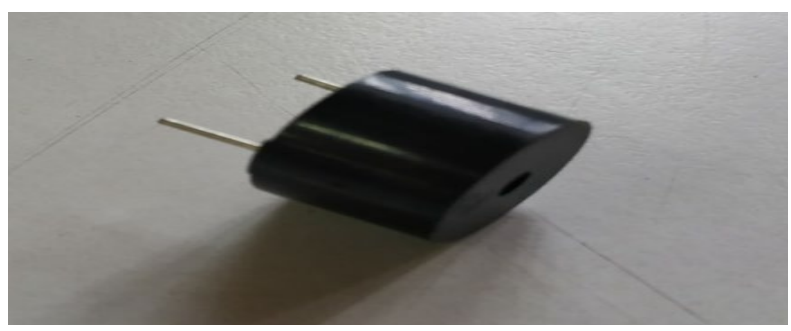

Fig.8. Buzzer [22]

It is a two pin device which gives sound component to our work Figure.8. The piezo signal produces sound dependent on the switch of the piezoelectric impact [14]. In our work, we have utilized a buzzer.

\section{Software technology : Arduino}

The program can be written in a programming language for a compiler to produces binary code. This code editor has salient features like syntax highlighting. It provides one-click mechanisms to compile and upload programs to an Arduino board. Our undertaking gives the Arduino incorporated advancement condition (IDE), which is a cross-stage application written in the programming language PYTHON. It has begun from the IDE for the dialects Handling and Wiring. [21]

\section{Developed model and methodology}

Our created model RFID based door access control utilizing Arduino Figure.9. depends on keen innovation where advanced information is encoded in RFID labels which are caught by the RFID reader by radio waves. These RFID labels have a working recurrence of $13.56 \mathrm{MHz}$ and $1 \mathrm{~Kb}$ of memory put away in it. The sign sent by the reader and antenna wire is utilized to control on the tag and mirror the vitality to the reader. When we switch on the power supply, the default white LED lights up, which demonstrates that the computerized framework is actuated. Each representative in the workplace has an ID card with explicit subtleties on it which can be followed by the RFID reader at whatever point it is put at a particular range. The RFID card tag of every representative is put away in the principle framework. Each time when a representative brings label near the RFID reader, the antenna wire in the reader sends a radio wave and reads the information of the RFID card. Every one of these activities are shown on the framework in the main office. At whatever point an individual with explicit ID label attempts to get into the limited territory, he/she needs to contact the card. On the off chance that the subtleties of that remarkable card are as of now put away in the framework, at that point the green LED lights and ringer rings up and the door opens consequently Figure 10. In the event that the subtleties on the card don't coordinate with the record put away in the framework, at that point the passage of that individual is denied. The door does not open and the red LED lights up with the ringer Figure 11. The door will naturally open and close when the privilege RFID tag is set inside the scope of RFID reader. The leader of the workplace has a master card through which the passage of another card can be made into the framework. Additionally, the information of ex-worker can be eradicated effectively utilizing the master 
card. When we contact the master card at the reader, the framework goes into the programming mode, after this when we contact the current card, the subtleties will be eradicated or the subtleties will be added to the framework and after this, the master card is contacted again at the reader to exit from the programming mode. On the other hand if the master card is lost, at that point, there is a reset button at the back. By pressing the button for 10 seconds, MasterCard information will be eradicated and new MasterCard can be instantiated. This framework is a simple and advantageous door get to framework which can upgrade the efficiency of labour.

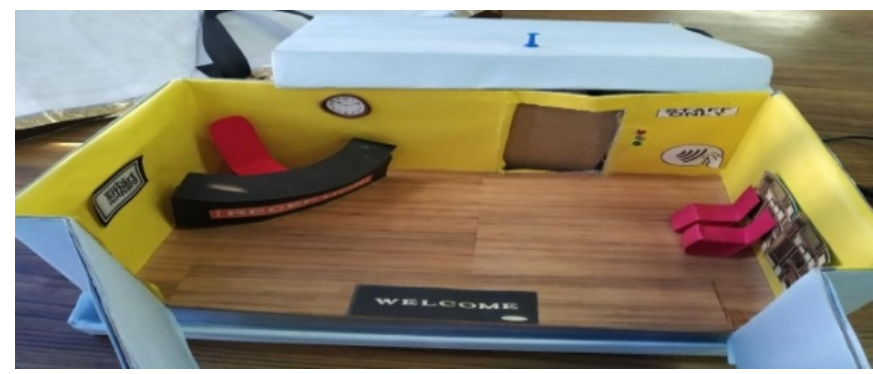

Fig. 9. Developed model [22]

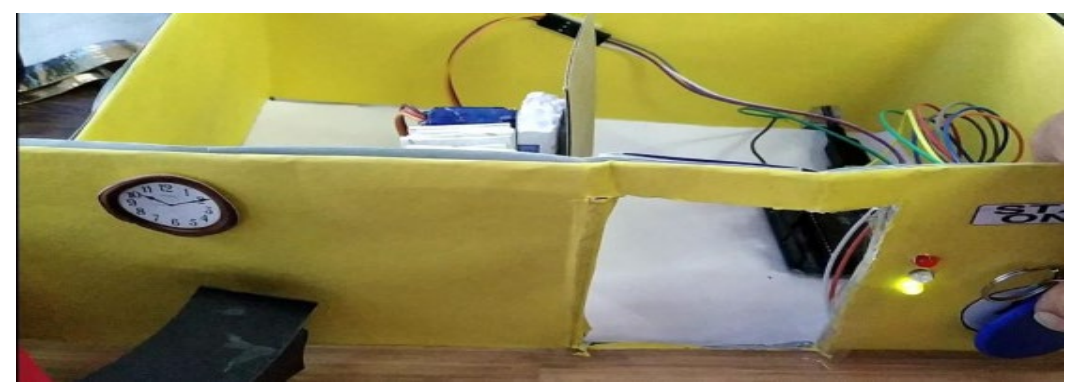

Fig. 10. Use of correct RFID tag[22]

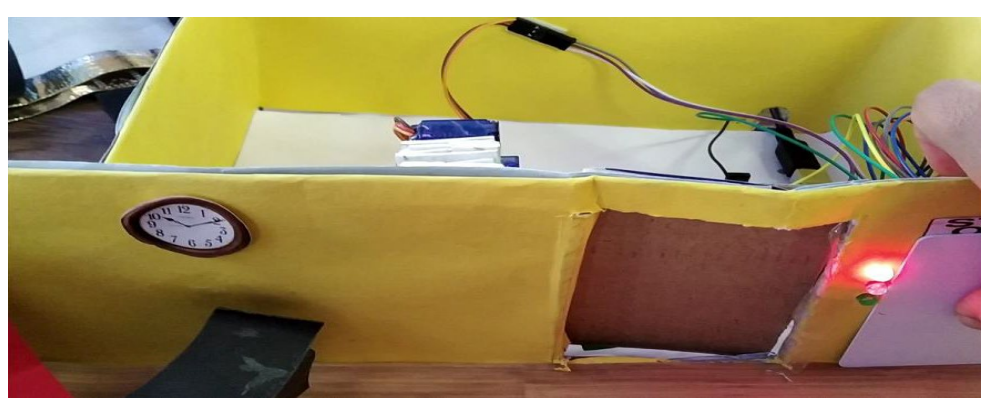

Fig. 11. Use of incorrect RFID [22] 


\section{Experimental circuit diagram}

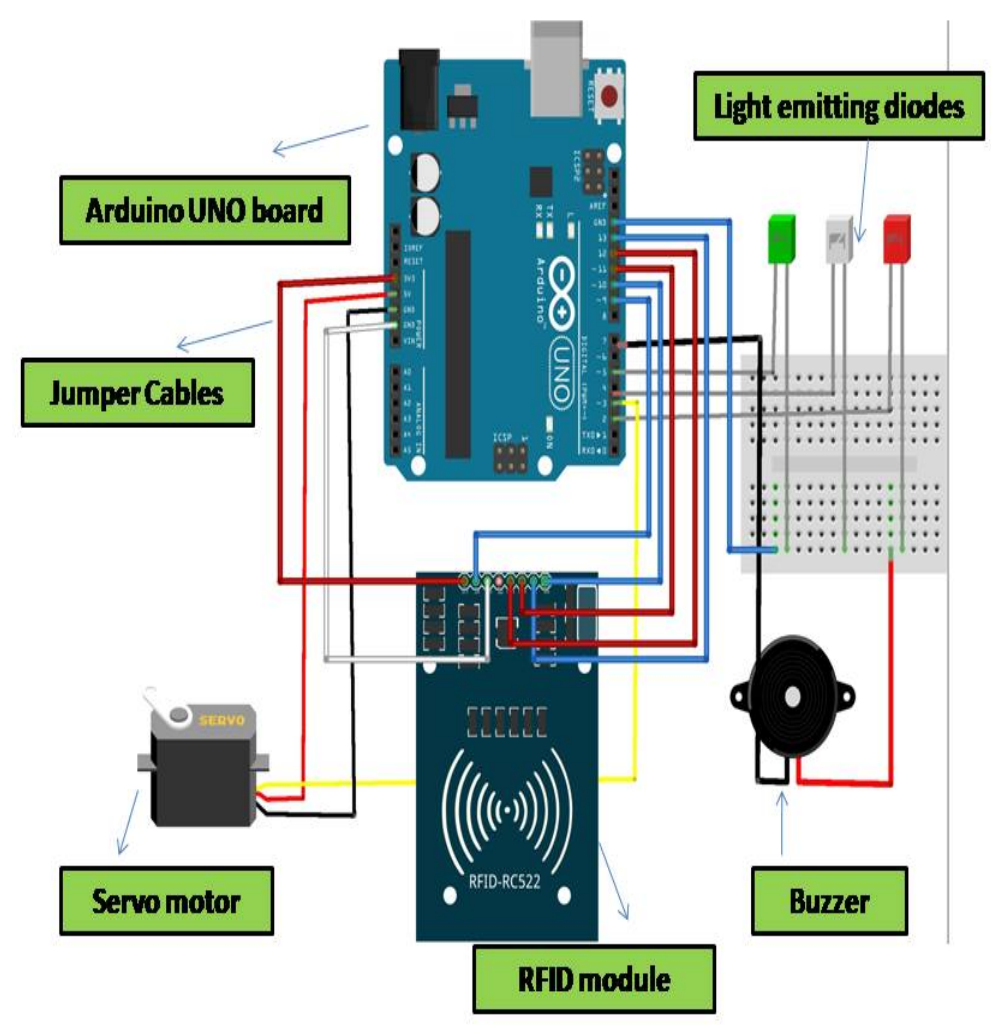

Fig. 12. Schematic diagram

Figure 12. demonstrates the appropriate schematic representation of the circuit prepared on fritzing. 


\section{System flow chart}

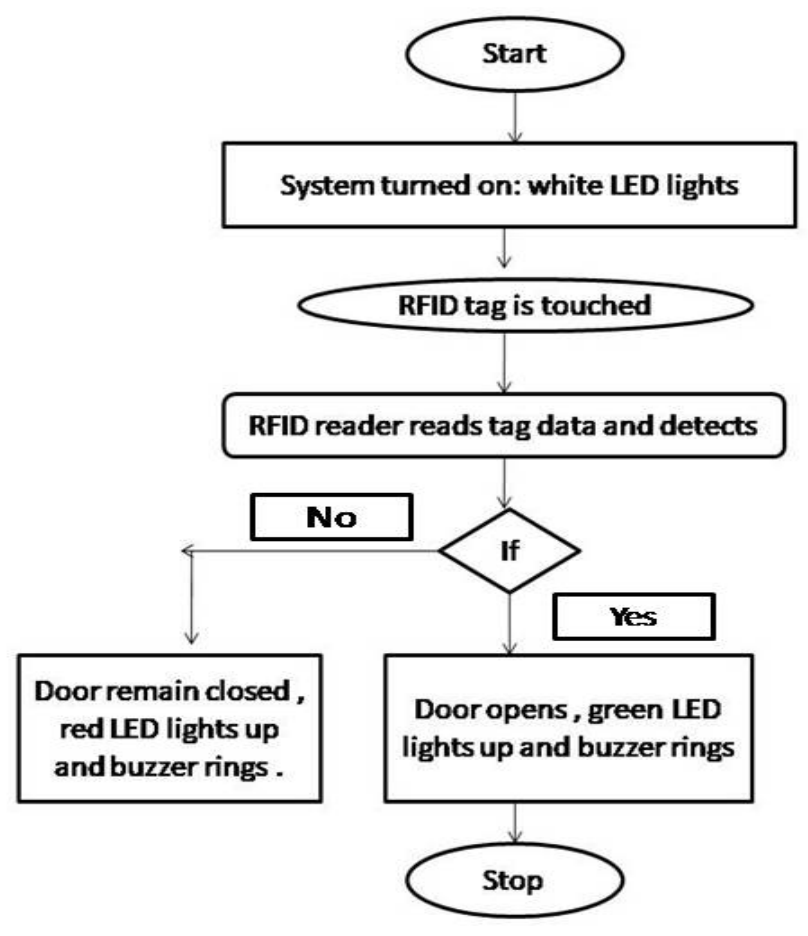

Fig. 13. Flow chart

Figure 13. illustrates the process flow of our system. The process begins as soon we supply voltage to the system .The system turns ON and white LED lights up. Now when we place the RFID tag on reader, the reader tries to match the data stored in the database program. If the data matches, white light turns green, buzzer rings and the door opens. Otherwise LED turns red and door remains closed and LED later turns back to white.

\section{Results and Conclusion}

RFID based security and access control framework is a quick and profoundly tied down framework when contrasted with some other biometric frameworks. It gives contact less correspondence and works without the observable pathway. With the assistance of Arduino, the framework are effectively open and works inconclusively. Clients can change the capacities in the Arduino code [18]. RFID control framework decreases human exertion and mistake. Also, with the assistance of this numerous RFID labels can be read at once which prompts high proficiency of RFID framework. Radio Frequency Identification (RFID) is a remote advancement that can be used to develop the passageway 
control framework. This innovation gives a progressive robotization in different procedures running from modern divisions to home control [19] [20].

\section{Acknowledgement}

I have a great pleasure in presenting this work on Automated door access based on RFID using Arduino and to express my deep gratitude towards those who have offered their valuable time \& guidance in my hour of need. It is a great honour to do this work in this esteemed institution, and I would like to express my sincere gratitude to $\mathrm{Mr}$ Faraz Ahmed who carefully and patiently leant his valuable time and effort to give directions as well as to correct various documents with attention and care.

\section{References}

[1] www.elprocus.com/understanding-about-types-of-access-control-systems/

[2] www.security.honeywell.com

[3] https://searchsecurity.techtarget.com

[4] www.vectorsecurity.com

[5] https://www.elprocus.com/automatic-door-lock-system-using-RFID-and-arduino/

[6] https://www.slideshare.net/naveeniift/RFID-and-its-applications

[7] www.fibre2fashion.com/industry-article/3271/RFID-applications

[8] https://blog.atlasRFIDstore.com/

[9] V. Subramanian, P. C. Chang, D. Huang, J. B. Lee, S. E. Molesa, D.

R. Redinger, and S. K.Volkman, "Printed organic transistors forultralowcostRFID applications", IEEE Transactions on Components and Packaging Technologies, 2005

[10] https://www.hackster.io/user8523373/RFID-based-automatic-door-system$7 \mathrm{~b} 2065$

[11] https://www.arduino.cc/

[12] www.camcode.com/asset-tags/what-are-RFID-tags/

[13] www.camcode.com/asset-tags/what-are-RFID-tags/

[14] https://en.wikipedia.org/wiki/Buzzer

[15] https://circuitdigest.com/article/servo-motor-basics

[16] https://en.wikipedia.org/wiki/Light-emitting_diode

[17] https://en.wikipedia.org/wiki/Jumper_cable

[18] A. JuelsRFID security and privacy: A research survey IEEE Journal on chosen areas in Computing, 24(2):381-394, February 2006.

[19]M. R. Rieback, B. Crispo, and A. S. Tanenbaum, "The Evolution of RFID Security"; PervasiveComputing, IEEE Volume 5, Issue 1, Jan.- Mar. 2006.

[20]Kamran Ahasan, Paul Kingston IEEE paper on "RFID applications: an introductory and exploratory study".

[21] https://www.arduino.cc/en/main/software

[22] Figure 3,4,5,6,7,8,9,10,12,13 are copyright- author 